\title{
Intermediate Filament Gene
}

National Cancer Institute

\section{Source}

National Cancer Institute. Intermediate Filament Gene. NCI Thesaurus. Code C30073.

Intermediate Filament Genes encode a number of different Intermediate Filament

Proteins (including keratin filaments, neurofilaments, desmin, and vimentin) that form polymeric structural cytoplasmic filaments, intermediate in diameter (8-10 nanometer) between actin microfilaments and microtubules, which comprise part of the cytoskeleton of most eukaryotic cells. (NCl) 